\title{
Role of ultrasound in predicting weaning failure in children undergoing cardiac surgery: Prospective observational study
}

\author{
Avneet Singh ${ }^{1}$, Banashree Mandal ${ }^{1}$, Goverdhan Puri ${ }^{1}$, Bharti Sidhu ${ }^{1}$, and Shyam \\ Thingnam ${ }^{1}$ \\ ${ }^{1}$ Post Graduate Institute of Medical Education and Research
}

October 16, 2020

\begin{abstract}
ABSTRACT Background: Increased extravascular lung water (EVLW) induced by systemic inflammatory response under cardiopulmonary bypass (CPB) and diaphragmatic dysfunction due to phrenic nerve injury during cardiac surgery leads to weaning failure from mechanical ventilation (MV) in pediatric patients undergoing cardiac surgery. We hypothesized that ultrasound measurement of EVLW shown by B-lines and diaphragm function in the form of thickening and excursion will be able to predict weaning failure defined as reintubation within 48 hours of endotracheal extubation in such patients. Methods: Fifty patients aged ( 1 month to 18 years) undergoing congenital cardiac surgeries were enrolled in the study. The ultrasound measurement of B-line of lung, diaphragm excursion (DE) and diaphragm thickness (DT) were done preoperatively, on pressure support ventilation (PSV) during weaning from mechanical ventilation (MV) and 4 hours after extubation. Results: 7 out of 50 patients had weaning failure. The patients with weaning failure (group $1, \mathrm{n}=7$ ) were younger, with median age of 1 year (0.25-7) compared to those who tolerated weaning (group 2, $\mathrm{n}=43$ ), median age of 3 years $(0.25-17)$, $\mathrm{p}=0.040$. The B-line score in group 1 increased from a preoperative score of 0 to post-extubation period score of 2 , the score being significantly higher than the patients of group $2(\mathrm{p}=0.024)$. The left diaphragm thickening fraction of $<17.15 \%$ predicted weaning failure with a sensitivity of $85 \%$, specificity of $51.4 \%$, (AUC ROC $0.75, \mathrm{p}=0.032$ ). Conclusion: LUS cannot predict weaning failure. The diaphragmatic thickening fraction $<17.15 \%$ was found to be a predictor of weaning failure in our patients.
\end{abstract}

\section{TITLE PAGE}

Type of article : Original

Title

Role of ultrasound in predicting weaning failure in children undergoing cardiac surgery: Prospective observational study

\section{Authors}

Avneet Singh, MD ${ }^{1}$; Banashree Mandal, MD, DM² , Goverdhan D Puri, MD, PhD ${ }^{3}$; Bharti Sidhu, MD ${ }^{4}$; KST Shyam MS, $\mathrm{MCh}^{5}$

\section{Authors Affiliation}

1- Fellow Cardiac Anaesthesia, Department of Anaesthesia and Intensive Care, Postgraduate Institute of Medical Education and Research, Chandigarh, India

Email: avneetsinghch@gmail.com

2- Additional Professor, Department of Anaesthesia and Intensive Care, Postgraduate Institute of Medical Education and Research, Chandigarh, India 
Email: banashreemandal@yahoo.co.in

3- Professor and Head of Department, Anaesthesia and Intensive Care, Postgraduate Institute of Medical Education and Research, Chandigarh, India

Email: gdpuri007@hotmail.com

4- Senior Resident Anaesthesia, Department of Anaesthesia and Intensive Care, Postgraduate Institute of Medical Education and Research, Chandigarh, India

Email: dr.bhartisidhu@gmail.com

5- Professor and Head of Department, Department of Cardiothoracic and Vascular Surgery, Postgraduate Institute of Medical Education and Research, Chandigarh, India

Email: s.thingnam@hotmail.com

\section{Corresponding Author}

Dr. Banashree Mandal, Additional Professor, Department of Anaesthesia and Intensive Care, PGIMER, Chandigarh

Room No 4015, C-Block, Advanced Cardiac Centre, PGIMER, Chandigarh, India, PIN-160012

E-mail: banashreemandal@yahoo.co.in, Phone: 8146266102, FAX: +91-172-2744401

Financial support received: None

Declaration of conflict of Interest: None

Meetings in which paper was presented:

$14^{\text {th }}$ Conference of Asian Society of Paediatric Anesthesiologists 2017

$65^{\text {th }}$ Annual Conference of Indian Society of Anesthesiologists 2017

$20^{\text {th }}$ Annual Conference of Paediatric Cardiac Society of India 2019

Total no of pages: 16

Total word count:

Abstract -250

Manuscript - 2196

\section{Running Title}

Ultrasound in predicting weaning failure in children undergoing cardiac surgery

Key words: Lung ultrasound, diaphragm ultrasound, weaning failure, mechanical ventilation, Pediatric cardiac surgery

Title: Role of ultrasound in predicting weaning failure in children undergoing cardiac surgery: Prospective observational study

INTRODUCTION

Weaning failure, defined as reintubation within 24-48 hours of extubation, has an incidence of $10 \%$ in postoperative pediatric cardiac surgical patients. ${ }^{1,2}$ The children undergoing cardiac surgery commonly develop pulmonary interstitial edema in the form of extravascular lung water (EVLW) collection as a result of inflammation mediated endothelial injury due to cardiopulmonary bypass (CPB) leading to prolonged mechanical ventilation (MV) . ${ }^{3-5}$ The incidence in mortality has been upto $31 \%$ in critically ill children with non-cardiac acute respiratory failure presenting with excess EVLW of $>10 \mathrm{ml} / \mathrm{kg}$. ${ }^{6}$ In addition to 
this, the inadvertent injury caused to the phrenic nerve during surgical manipulation, cold ice slush used in the pericardial cradle may cause diaphragmatic palsy (DP). ${ }^{3-5}$ The incidence of DP after cardiac surgery is $0.3-12.8 \%{ }^{7}$ It may present with postoperative respiratory distress, atelectasis, recurrent pneumonia or difficulty to wean from mechanical ventilation. ${ }^{1}$

Commonly used weaning indices are maximum inspiratory pressure, rapid shallow breathing index (RSBI), tracheal airway occlusion pressure at $0.1 \mathrm{~s}$, CROP index and leak test which can be performed to assess the extubation readiness. However, these indices are influenced by the combined functions of diaphragm, intercostal muscles, abdominal muscles and the compliance of the rib cage. Serial chest X-rays are routinely used to assess the post operative EVLW. ${ }^{8,9}$ However, CXRs may be inaccurate when supine radiographs are used. The progressive elevation of hemi-diaphragm visualized on CXR suggest diaphragm palsy but the cumulative radiation dose given to the child will be very high. ${ }^{8-13}$ Fluoroscopy guided Sniff test, phrenic nerve conduction study and trans-diaphragmatic pressure movements are used for the assessment of the diaphragm but they are invasive procedures, have high radiation exposure, not easily available in all centers and involve transport of patient from ICU to the concern department for the investigation. ${ }^{13}$

EVLW and diaphragm function can be easily measured and quantified at the post-operative bedside by ultrasonography by the Intensivists. ${ }^{14-17}$ This has a very small learning curve, can be followed in real time. However, the data on the feasibility and utility of B-lines and Diaphragm excursion and thickness measurements in post-operative pediatric patients is sparse. ${ }^{18}$

In this study, we hypothesized that the severity of lung interstitial edema (EVLW) as shown by B-lines and diaphragm dysfunction measured by ultrasound, can be used as predictors of weaning failure from mechanical ventilation in pediatric patients undergoing cardiac surgery. The primary aim of our study was to observe the correlation between weaning failure, which we defined as re-intubation within 24-48 hours of extubation and ultrasonic assessment of EVLW and Diaphragm function in pediatric patients on MV after cardiac surgery and secondarily to observe correlation between weaning failure and other indices of weaning from mechanical ventilation, $\mathrm{PaO} 2 / \mathrm{Fio} 2$ (PF ratio )ratio, rapid shallow breathing index,(RSBI) duration of mechanical ventilation and use of non-invasive ventilation and length of intensive care unit stay.

\section{METHODS}

\section{Informed Consent}

This prospective observational study was carried out after institute's internal ethics committee clearance (INT/IEC/2016/2540) and CTRI registration (CTRI/2018/02/011677). Written informed consent were taken from parents or legal guardians of the patients.

\subsection{Subjects}

Patients aged 1 month to 18 years undergoing cardiac surgery under CPB were enrolled in the study. The patients whose parents /legal guardians refused consent, or those with dressing at the ultrasound site were excluded from the study.

\subsection{Ventilatory management}

In the postoperative period, all patients were shifted to cardiothoracic surgical intensive care unit for elective mechanical ventilation (MV). The patients were weaned from MV upon the judgment of the attending intensivist. The patients were brought to the minimum pressure support ventilation support $(5 / 5)$ of CPAP and pressure support ventilation (PSV) and then extubated according to our institute's protocol of observing the $\mathrm{PF}$ ratio $>250, \mathrm{RSBI}<150$. Our ultrasound measurements did not interfere with the planned extubation or reintubation.

\subsection{Lung USG (Figure 1)}

The scanning for B-lines was done according to the protocol provided previously by Lichentstein and Targetta in their studies ${ }^{14,15}$. We used a 8 or 12 quadrant model depending upon the height of our patients and the entire thorax was scanned using 7-13 MHz linear probe, Sonosite M-Turbo Platform, (FUJIFILM SonoSite, 
Inc, USA) at the mid-clavicular and the mid-axillary lines, as shown in the figures 1,2. ${ }^{19-21}$ The B-lines were semi quantified and given a score using the LUS scoring scale. ${ }^{22}$

\subsection{Diaphragm USG (Figure 2)}

The 3-5 MHz curvilinear probe was placed at the right and left subcostal areas at the anterior axillary lines and directed medially and cranially. The M-mode was used to assess the diaphragm excursion and thickness. The amplitude of excursion of the diaphragm was measured on the vertical axis as the distance between the baseline to the maximum height of inspiration and expiration on the M-mode tracing ${ }^{23}$. The maximum thickness of diaphragm during inspiration (I) and expiration (E) was also measured.

\subsection{Statistical Analysis}

The normality of quantitative data was checked by Kolmogorov Smirnov test. The data presentation was done as mean and standard deviation; median and inter-quartile range. The parametric data was analyzed using Student t-test. Non- parametric data was analyzed using Mann-Whitney test. The comparison of time related variables was done using Repeated Measures ANOVA. Correlation between the variables was calculated using Spearman's correlation. The patients were divided into two groups- group 1: reintubation and group 2 : non-reintubation and the two groups were compared. The receiver operating characteristic (ROC) curves were drawn to find maximal cut-off values that could predict weaning failure. All statistical tests were two-sided and p-value [?]0.05 was considered as significant. Analysis was conducted using SPSS for Windows (version 22.0; SPSS Inc., Chicago, IL, USA)

\section{RESULTS}

\subsection{Demographic characteristics (Table 1)}

50 patients were enrolled into our study, out of which 7 children were reintubated within 48 hours of extubation (group 1). The patients in group 1 were younger in age compared to group 2, median age 1 (0.25-7) year vs $3(0.25-17)$ years; $\mathrm{p}=0.040$, and an age less than 1.5 years correlated with weaning failure with a sensitivity of $71 \%$ and specificity of $68 \%$. The study groups were comparable with respect to their sex, basal metabolic index (BMI), surgical procedures performed, minimum intraoperative temperature, $\mathrm{CPB}$ and aortic cross clamp times fluid balance at the end of CPB and before extubation in ICU and echocardiographic parameters. The MV duration was significantly prolonged in-group 1 ( 23.50 hours vs. 13 hours, $\mathrm{p}=0.019)$ and had more frequent use of non - invasive ventilation (NIV) $(42.8 \%$ vs. $7 \%, \mathrm{p}=0.029)$. The total ICU stay days was significantly longer in-group 1 (9 days vs 3 days, $\mathrm{p}=0.02$ ).

\subsection{Lung ultrasound scores (LUS) (Figure 3)}

In both the groups the LUS score increased from baseline to PSV and but continued to be increased into post-extubation period in group 1 (score 1 vs 2 ; p-value 0.024 ); whereas they decreased in-group 2 in the post-extubation period (score 1 vs 1 ). There was no significant difference between the LUS scores between the two groups at the three time points. Similarly, the total number of B-lines increased from baseline to PSV in both the groups, but after extubation decreased significantly in group-2 (B lines 12 vs 9 ), but continued to increase in group-1(B lines 9 vs 19).

\subsection{Diaphragm ultrasound characteristics (Table2, 3)}

The diaphragm excursion (DE) decreased from baseline to the PS period and recovered quickly after extubation even though the values continued to remain lower than the baseline in both the groups. The two groups did not show any significant difference between the diaphragm excursions or in the thickness. The left diaphragm thickening fraction (DTF) was significantly reduced in group 1 as compared to group 2(13.71 $\%$ vs $25.26 \%, \mathrm{p}=0.035)$ during PSV.

3.4 Predictors of prolonged mechanical ventilation duration and weaning failure (Figure 4, 5 , 6) 
Age $<1.5$ years can predict weaning failure with a sensitivity of $71 \%$ and specificity of $68 \%$. The LUS scores and DE did not have any significant correlation with weaning failure or mechanical ventilation duration and ICU stay days. We found the baseline right diaphragm thickness value of $<24 \mathrm{~mm}$ could predict MV duration of $>13$ hours with $(70 \%$ sensitivity and $70 \%$ specificity) and AUC of $0.68, p=0.026$. The left diaphragm thickening fraction on PSV with a cut-off value of $17.15 \%$ was found as a predictor for the weaning failure (sensitivity $85 \%$, specificity $49 \%$, AUC ROC $0.75, \mathrm{p}=0.032$ ).

\section{DISCUSSION}

In this observational study we tried to identify the bedside ultrasonic predictors of weaning failure from mechanical ventilation in pediatric patients who underwent cardiac surgery under cardiopulmonary bypass. The pulmonary complications of CPB can be manifested by the presence of B-lines and diaphragm dysfunction. 24-29

We found the median LUS score to increase from baseline to PSV (post operatively) in concurrence with the previous literatures ${ }^{21,22,29,41}$.The significant elevation of the scores in the postextubation period in group 1 may be the reason for the weaning failure, whereas in the group 2 the scores remained the same postextubation. However, we did not find any correlation between LUS scores and the events of weaning failure. This can be attributed to the fact that the post cardiac surgery lung edema is of multifactorial origin. ${ }^{12-14}$ The similar intraoperative management with a negative fluid balance after CPB and before extubation (table 1) and cardiac functions maybe the reason for the similar lung profiles for both the groups. The cardiogenic pulmonary edema did not contribute significantly to the LUS scores of our patients, and the LVEF and E/e' did not differ between the two groups of patients. The fluid balance measured before extubation corelated significantly with MV duration $\left(\mathrm{r}^{2}=0.471, \mathrm{p}=0.001\right)$ and ICU stay days $\left(\mathrm{r}^{2}=0.297, \mathrm{p}=0.038\right)$, suggesting the patients with negative fluid balance have favorable outcomes.

We could establish the relevance of TDF value of less than $17.15 \%$ (sensitivity of $85 \%$ ) of the left side diaphragm during the PSV in predicting the weaning failure .The diaphragm contributes to $75 \%$ of respiratory effort in children, as evidenced by a DTF less than $17.15 \%$ with increased rates of reintubation. The DTF less than 17\%- $21 \%$ during SBT in children have been shown to be associated with extubation failure. 42 This study was conducted in medical ICU patients with longer times of intubation prior to giving an extubation trial, which could have resulted in greater diaphragm remodeling as compared to our subset of patients who were intubated for a short duration. These studies measured the diaphragm only on the right side which was easier to visualize. In our study, we found significant changes of the diaphragm on the left side only. This could be due to the fact that there is frequent handling of the phrenic nerve on the left side.

The diaphragm atrophy rate is $3.4 \%$ per day in children. ${ }^{43}$ There was a decrease of thickness values during the pressure support mode of ventilation in our patients. There are no defined reference values of normal diaphragm thickness in children, so we used the pre-operative baseline values as our reference. These values were lower than the values measured by Glau et al of $2 \mathrm{~cm}(1.8-2.5)$ measured in children with acute respiratory failure, as our patients were critically ill cardiac patients who might have had compensated respiratory problems prior to surgery.

The diaphragm excursion is decreased after mechanical ventilation even four hours after extubation (group 1 :p-value -0.022; group 2 : p-value -0.00), suggesting the detrimental effects of neuromuscular blockers and mandatory ventilation on diaphragm functions. However, the diaphragm excursion has limited predictive ability for weaning outcomes. ${ }^{32,} 40,42$ The excursion may be influenced by the pressure provided by the ventilator leading to a similar degree of excursion despite significantly different levels of muscle efforts , whereas thickness is influenced only by active contraction.

The DE and TDI have been used to assess the feasibility of extubation during SBT in the adult patients on prolonged mechanical ventilation; however its suitability to be used during the weaning process in pediatric patients after cardiac surgery has not been clearly established. ${ }^{31-35}$

\section{CONCLUSION}


LUS scores cannot predict weaning failure whereas diaphragmatic thickening fraction during SBT $<17.15 \%$ was found to be a predictor of weaning failure in pediatric post cardiac surgical patients.

Our study was limited by the fact that we had a short time course and we did not follow the patients in the post extubation period beyond 4 hours in non-reintubated patients. Our study had heterogeneous patient population undergoing variety of procedures having very different surgical procedures and their effect on the kids. So the cut -off values may not be applied generalized to all pediatric patients. We had a small sample size, which could have made the significant results appear non-significant. We did not evaluate the concurrent effects of lung compliance on the extubation outcomes. We did not evaluate EVLW or diaphragm dysfunction by other known methods like Trans diaphragmatic pressure movements, Fluoroscopy, Phrenic

nerve conduction studies. In future, the study can be expanded to the learning of the long-term effects of $\mathrm{CPB}$ on mechanical ventilation. The study can be extended onto non-CPB surgery patients.

\section{ACKNOWLEDGEMENTS}

We thank the OR technical assistants and ICU nursing officers assistance during the study process.

\section{CONFLICTS OF INTERESTS}

The authors declare that there are no conflicts of interests.

\section{AUTHOR CONTRIBUTIONS}

AS, BM, BS, GDP and SKST designed the study. AS, BM and BS wrote the manuscript. AS performed the lung and diaphragm ultrasound. AS and BM performed the data analysis. All the authors edited the manuscript.

\section{BIBLIOGRAPHY}

1. Newth CJL, Venkataraman S, Willson DF, Meert KL, Harrison R, Dean JM, Pollack M, Zimmerman J, Anand KJ, Carcillo JA et al. Weaning and Extubation Readiness in Pediatric Patients. Pediatr Crit Care Med 2009; 10: 111.

2. Harrison AM, Cox AC, Davis S, Piedmonte M, Drummond-Webb JJ, Mee RB. Failed extubation after cardiac surgery in young children: Prevalence, pathogenesis, and risk factors Pediatr Crit Care Med 2002; 3:148-52.

3. Apostolakis E, Filos KS, Koletsis E, Dougenis D; Lung Dysfunction Following Cardiopulmonary Bypass; J Card Surg 2010; 25:47-55.

4. Dönmez A, Yurdakök O: Cardiopulmonary Bypass in Infants; Journal of Cardiothoracic and Vascular Anesthesia 2014; 28:778-88.

5. Stayer SA, Diaz LK, East DL, Gouvion JN, Vencill TL, McKenzie ED, Fraser CD,Andropoulos DB et al; Changes in Respiratory Mechanics Among Infants Undergoing Heart Surgery; Anesth Analg 2004; 98:49 -55 .

6. Lubrano R, Cecchetti C, Elli M, Tomasello C, Guido G, Di Nardo M, Masciangelo R, Pasotti E, Barbieri MA, Bellelli E. Prognostic value of extravascular lung water index in critically ill children with acute respiratory failure. Intensive Care Med 2011; 37:124-31.

7. Joho-Arreola AL, Bauersfeld U, Stauffer UG, Baenziger O, Bernet V. Incidence and treatment of diaphragmatic paralysis after cardiac surgery in children. Eur J Cardiothorac Surg 2005; 27:53-7.

8. Balaji S, Kunovsky P, Sullivan I. Ultrasound in the diagnosis of diaphragmatic paralysis after operation for congenital heart disease. Br Heart J 1990; 64:20-2.

9. Ferrari G, De Filippi G, Elia F, Panero F, Volpicelli G, Aprà F . Diaphragm ultrasound as a new index of discontinuation from mechanical ventilation. Crit Ultrasound J 2014; 6:8.

10. Kim WY, Suh HJ, Hong SB, Koh Y, Lim CM. Diaphragm dysfunction assessed by ultrasonography: influence on weaning from mechanical ventilation. Crit Care Med 2011;39:2627-30 .

11. Urvoas E, Pariente D, Fausser C, Lipsich J, Taleb R, Devictor D. Diaphragmatic paralysis in children: diagnosis by TM-mode Ultrasound . Pediatr Radiol 1994;24:564-8. 
12. Sanchez TJ, Munoz R, Landsittel D, Shiderly D, Yoshida M, Komarlu R, Wearden P, Morell VO, Chrysostomou C. Diagnosis of abnormal diaphragm motion after cardiothoracic surgery: ultrasound performed by a cardiac intensivist vs. fluoroscopy . Congenit Heart Dis 2010; 5:565-72.

13. Kim WY, Suh HJ, Hong SB, Koh Y, Lim CM. Diaphragm dysfunction assessed by ultrasonography: influence on weaning from mechanical ventilation. Crit Care Med 2011; 39:2627-30 .

14. Targhetta R, Chavagneux R, Balmes P, Lemerre C, Mauboussin JM, Bourgeois JM, Pourcelot L. Sonographic lung surface evaluation in pulmonary sarcoidosis: preliminary results. J Ultrasound Med 1994; 13:381-8.

15. Lichtenstein DA, Mauriat P. Lung Ultrasound in the Critically Ill Neonate. Current Pediatric Reviews 2012; 8: 217-23.

16. Lichtenstein D, Mezière G, Lagoueyte JF, Biderman P, Goldstein I, Gepner A. A-lines and B-lines: Lung ultrasound as a bedside tool for predicting pulmonary artery occlusion pressure in the critically ill. Chest 2009; 136: 1014-20.

17. De Leeuw M, Williams JM, Freedom RM, Williams WG,Shemie SD, McCrindle BW . Impact of diaphragmatic paralysis after cardiothoracic surgery in children. J Thorac Cardiovasc Surg 1999 ;118:510-7.

18. Cantinotti M, Giordano R, Scalese M, Marchese P, Franchi E, Viacava C,Molinaro S, Assanta N, Koestenberger M, Kutty S, Gargani L, Ait-Ali L. Prognostic Value of a New Lung Ultrasound Score to Predict Intensive Care Unit Stay in Pediatric Cardiac Surgery. Ann Thorac Surg. 2020;109:178-84.

19. Lichtenstein D, Mezière G, Lagoueyte JF, Biderman P, Goldstein I, Gepner A. A-lines and B-lines: Lung ultrasound as a bedside tool for predicting pulmonary artery occlusion pressure in the critically ill. Chest 2009; 136: 1014-20.

20. Volpicelli G, Mussa A, Garofalo G, Cardinale L, Casoli G, Perotto F, Fava C,Frascisco M.Bedside lung ultrasound in the assessment of alveolar-interstitial syndrome. Am J Emerg Med 2006; 24:689-96.

21. Volpicelli G, Caramello V, Cardinale L, Mussa A, Bar F, Frascisco MF. Bedside ultrasound of the lung for the monitoring of acute decompensated heart failure. Am J Emerg Med 2008; 26: 585-91.

22. Gargani L. Lung ultrasound: a new tool for the cardiologist. Cardiovascular Ultrasound 2011; 9:6.

23. Epelman M, Navarro OM, Daneman A, Miller SF. M-mode sonography of diaphragmatic motion: description of technique and experience in 278 pediatric patients. Pediatr Radiol 2005; 35: 661-67.

24. Pasero D, Koeltz A, Placido R, Fontes Lima M, Haun O, Rienzo M, Marrache D, Pirracchio R, Safran D, Cholley B. Improving ultrasonic measurement of diaphragmatic excursion after cardiac surgery using the anatomical M-mode: a randomized crossover study. Intensive Care Med. 2015;41:650-6.

25. Jellish WS, Oftadeh M. Peripheral Nerve injury in cardiac surgery. J Cardiothorac Vasc Anesth 2018;32:495-511.

26. Cohen AJ, Katz MG, Katz R. Phrenic nerve injury after coronary artery grafting: Is it always benign? Ann Thorac Surg 1997;64:148-53.

27. Aguirre VJ, Sinha P, Zimmet A, Lee GA, Kwa L, Rosenfeldt F. Phrenic nerve injury during cardiac surgery: Mechanisms, management and prevention. Heart Lung Circ 2013; 22:895-902.

28. Bignami E, Guarnieri M, Saglietti F, Ramelli A, Vetrugno L. Diaphragmatic dysfunction following cardiac surgery: Is there a role for pulmonary ultrasound? J Cardiothorac Vasc Anesth 2018;32: e6-7.

29. Kaskinen AK, Martelius L, Kirjavainen T, Rautiainen P,Andersson S ,Pitkanen OM. Assessment Of Extravascular Lung Water By Ultrasound After Congenital Cardiac Surgery. Pediatr Pulmonol 2017; $52: 345-52$.

30. Vetrugno L, Guadagnin GM, Barbariol F, Langiano N, Zangrillo A, Bove T. Ultrasound Imaging for Diaphragm Dysfunction: A Narrative Literature Review. J Cardiothorac Vasc Anesth. 2019;33:2525-36.

31. De Leeuw M, Williams JM, Freedom RM, Williams WG,Shemie SD, McCrindle BW . Impact of diaphragmatic paralysis after cardiothoracic surgery in children. J Thorac Cardiovasc Surg 1999 ;118:510-7.

32. Vivier E, Mekontso Dessap A, Dimassi S, Vargas F, Lyazidi A, Thille AW,Brochard L. Diaphragm ultrasonography to estimate the work of breathing during non-invasive ventilation. Intensive Care Med 2012;38:796-803.

33. Umbrello M, Formenti P. Ultrasonographic assessment of diaphragm function in critically ill subjects. Respiratory Care 2016;61:542-55. 
34. Boon AJ, Harper CJ, Ghahfarokhi LS, Strommen JA, Watson JC, Sorenson EJ.. Two-dimensional ultrasound imaging of the diaphragm: Quantitative values in normal subjects. Muscle Nerve 2013;47:8849.

35. Harper CJ, Shahgholi L, Cieslak K, Hellyer NJ, Strommen JA, Boon AJ. Variability in diaphragm motion during normal breathing, assessed with B-mode ultrasound. J Orthop Sports Phys Ther 2013;43:92731.

36. Ali ER, Mohamad AM. Diaphragm ultrasound as a new functional and morphological index of outcome, prognosis and discontinuation from mechanical ventilation in critically ill patients and evaluating the possible protective indices against VIDD. Egypt J Chest Dis Tuberc 2017; 66:339-51.

37. Volpicelli G, Elbarbary M, Blaivas M, Lichtenstein DA, Mathis G, Kirkpatrick AW, Melniker L, Gargani L, Noble VE, Via G. et al. International evidence-based recommendations for point-of-care lung ultrasound. Intensive Care Med 2012; 38:577-91.

38. Raimondi F, Migliaro F, Sodano A, Umbaldo A, Romano A, Vallone G, Capasso L. Can neonatal lung ultrasound monitor fluid clearance and predict the need of respiratory support. Crit Care 2012; 16:220.

39. Martelius, L, Heldt H, Lauerma K. B-Lines on Pediatric Lung Sonography Comparison With Computed Tomography. J Ultrasound Med 2016; 35:153-57.

40. Umbrello M, Formenti P, Longhi D, Galimberti A, Piva I, Pezzi A, Mistraletti G, Marini JJ, Iapichino G. Diaphragm ultrasound as indicator of respiratory effort in critically ill patients undergoing assisted mechanical ventilation: a pilot clinical study. Crit Care. 2015;19:161

41. Apostolakis E, Filos KS, Koletsis E, Dougenis D; Lung Dysfunction Following Cardiopulmonary Bypass; J Card Surg 2010; 25:47-55.

42. Xue, Y., Zhang, Z., Sheng, C. et al. The predictive value of diaphragm ultrasound for weaning outcomes in critically ill children. BMC Pulm Med . 2019 19: 270.

43. Glau CL, Conlon TW, Himebauch AS, et al. Progressive Diaphragm Atrophy in Pediatric Acute Respiratory Failure. Pediatr Crit Care Med . 2018;19:406-11.

\section{Hosted file}

Table Legend final.pdf available at https://authorea.com/users/367836/articles/487099-roleof-ultrasound-in-predicting-weaning-failure-in-children-undergoing-cardiac-surgeryprospective-observational-study

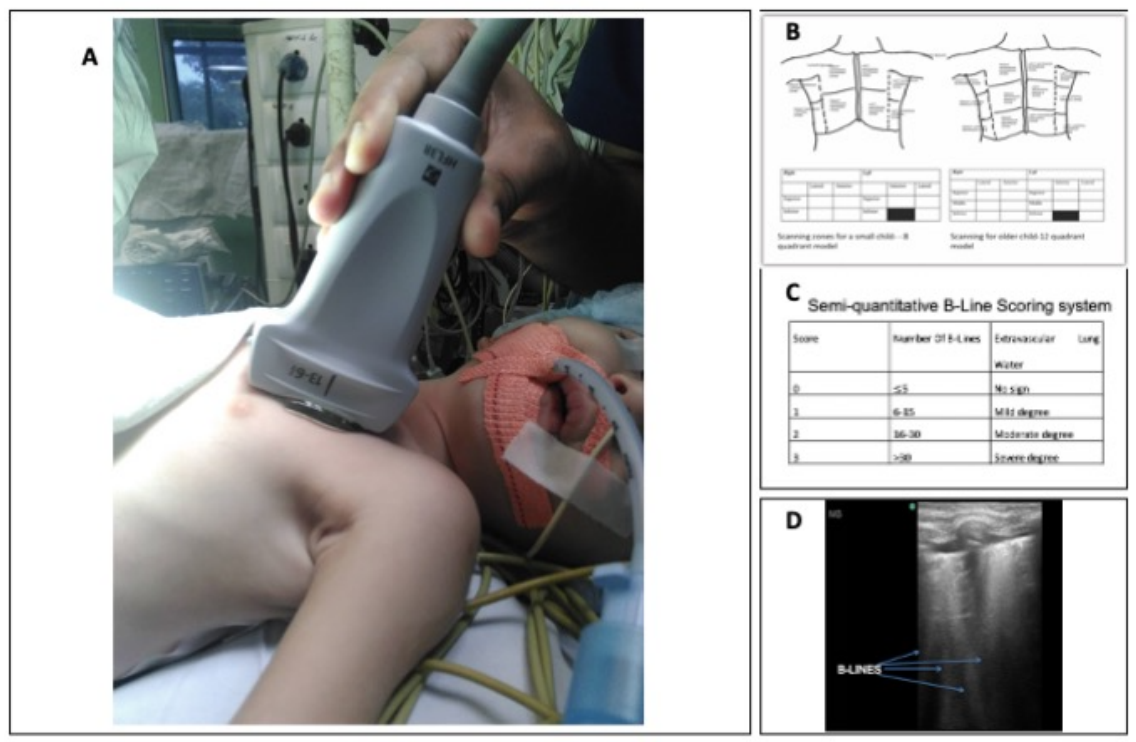



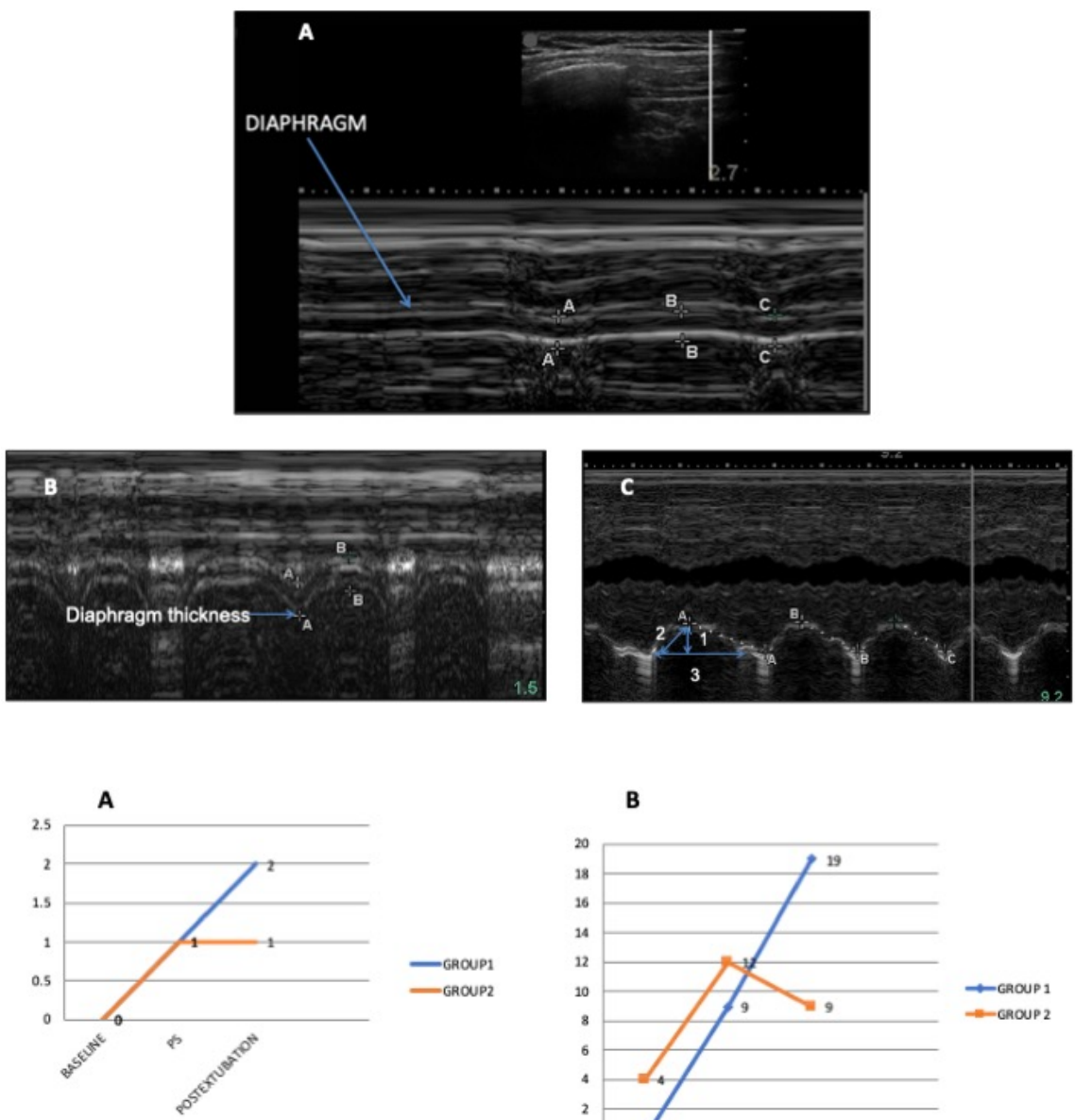

\begin{tabular}{|c|c|c|c|c|}
\hline Outcome & Baseline & PS & Post- & p-value \\
\hline Group 1 & $0(0-1)$ & $1(0-2)$ & $2(1-3)$ & $\begin{array}{l}0.527^{\circ} \\
0.059^{*} \\
0.20\end{array}$ \\
\hline Group 2 & $0(0-3)$ & $1(0-3)$ & $1(0-3)$ & $\begin{array}{l}0.001^{\wedge} \\
0.063^{*} \\
0.080\end{array}$ \\
\hline p-value & 0.743 & 0.258 & 0.083 & \\
\hline
\end{tabular}

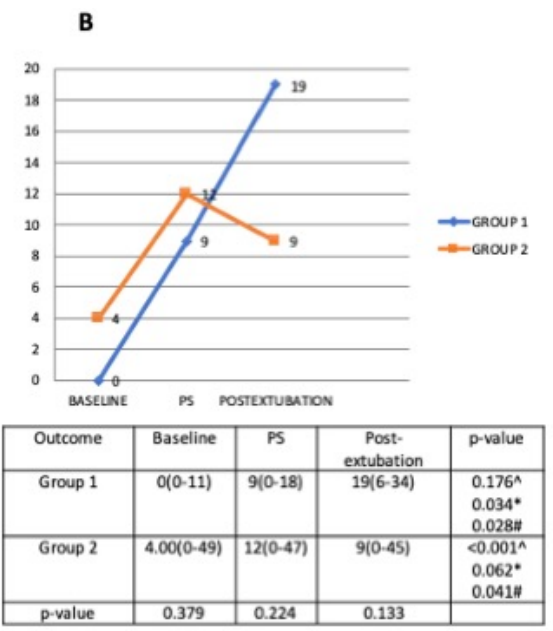




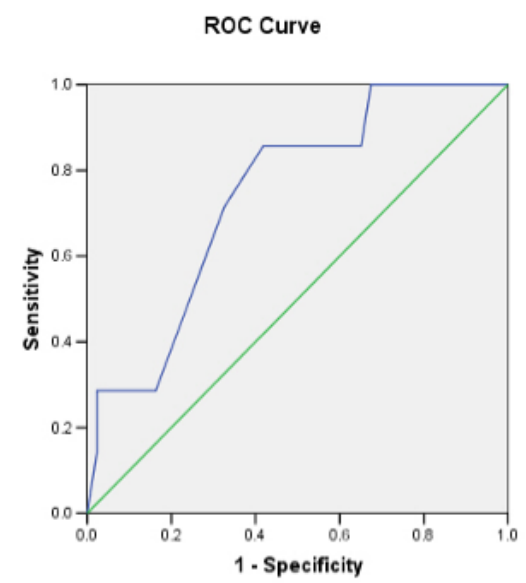

Diagonal segments are produced by ties.

Area Under the Curve (AUC)

Test Result Variable(s): AGE (yrs.) vs weaning failure

\begin{tabular}{|r|r|r|r|r|}
\hline \multirow{2}{*}{ Area } & \multirow{2}{*}{ Std. Error (a) } & \multirow{2}{*}{$\begin{array}{c}\text { Asymptotic } \\
\text { Sig. (b) }\end{array}$} & \multicolumn{2}{|c|}{$\begin{array}{c}\text { Asymptotic 95\% Confidence } \\
\text { Interval }\end{array}$} \\
\cline { 4 - 5 } & & & Lower Bound & Upper Bound \\
\hline .743 & .090 & .041 & .565 & .920 \\
\hline
\end{tabular}

The test result variable(s): AGE (yrs) has at least one tie between the positive actual state group and the negative actual state group. Statistics may be biased.

a Under the nonparametric assumption

b Null hypothesis: true area $=0.5$ 


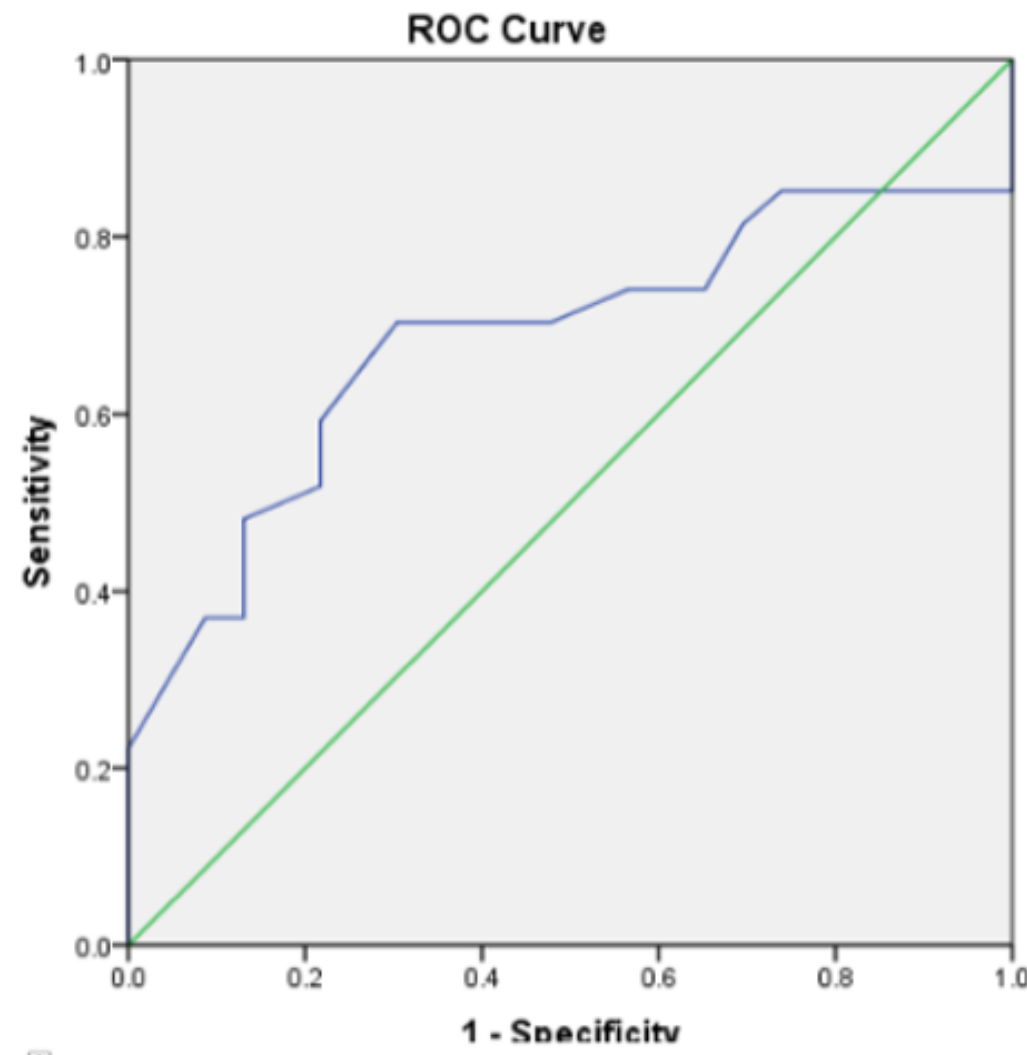

$\oplus$

Area Under the Curve

Test Result Variable(s): RT BASE EXP THICKNESS Vs Mechanical ventilation duration

\begin{tabular}{|c|c|c|c|c|}
\hline \multirow[b]{2}{*}{ Area } & \multirow[b]{2}{*}{ Std. Error ${ }^{\circ}$} & \multirow[b]{2}{*}{ Asymptotic Sig. P } & \multicolumn{2}{|c|}{ Asymptotic $95 \%$ Confidence Interval } \\
\hline & & & Lower Bound & Upper Bound \\
\hline .684 & .078 & .026 & .531 & .836 \\
\hline
\end{tabular}

The test result variable(s): RT BASE EXP THICKNESS has at least one tie between the positive actual state group and the negative actual state group. Statistics may be biased.

a. Under the nonparametric assumption

b. Null hypothesis: true area $=0.5$ 


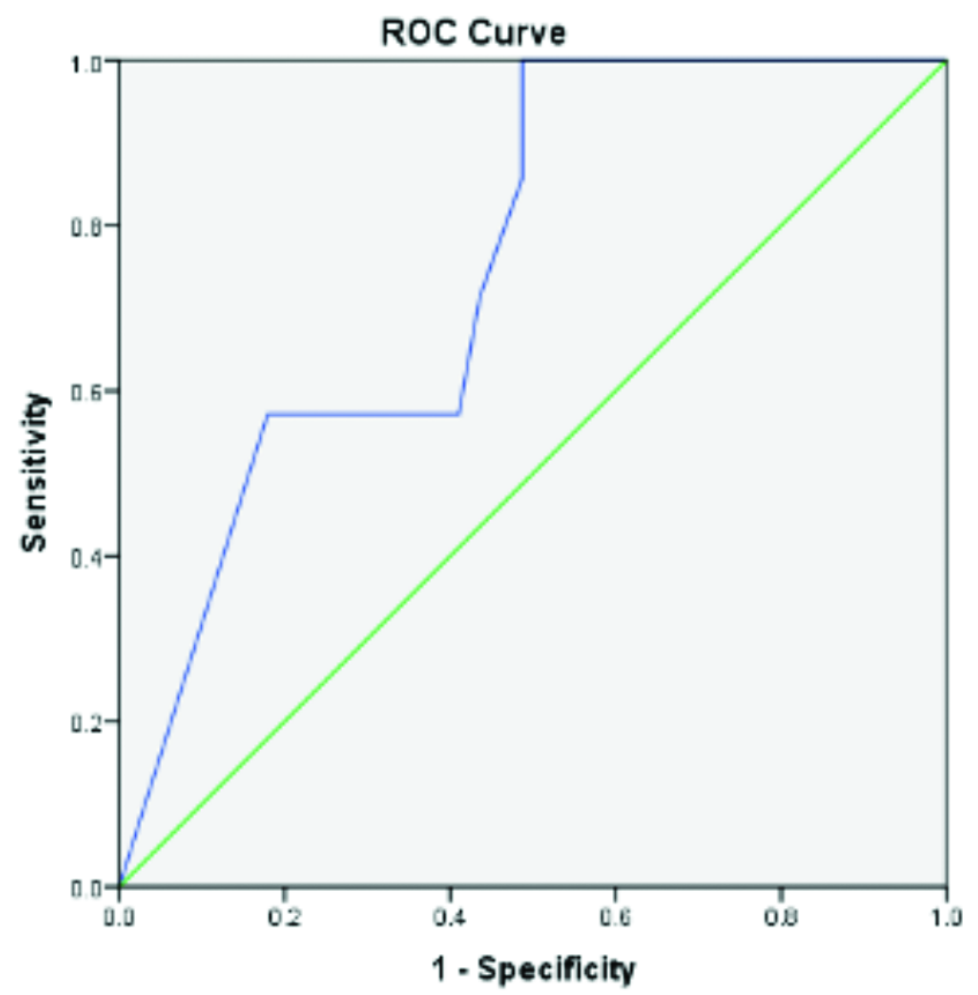

Diagonal segments are produced by ties

\section{Area Under the Curve}

Test Result Variable(s): It ps thickeing \%

\begin{tabular}{|r|r|r|r|r|}
\hline & & & \multicolumn{2}{|c|}{ Asymptotic 95\% Confidence Interval } \\
\cline { 4 - 5 } Area & Std. Error & Asymptotic Sig. & Lower Bound & Upper Bound \\
\hline .753 & .086 & .035 & .584 & .921 \\
\hline
\end{tabular}

The test result variable(s): It ps thickeing $\%$ has at least one tie between the positive actual state group and the negative actual state group. Statistics may be biased.

a. Under the nonparametric assumption

b. Null hypothesis: true area $=0.5$ 